\title{
Evaluation of Sprayed Fluorescent Pigment as a Method to Mass-Mark Fish Species
}

\author{
David A. Schumann ${ }^{1}$, Keith D. Koupal ${ }^{2, *}$, W. Wyatt Hoback ${ }^{1}$ and Casey W. Schoenebeck ${ }^{1}$ \\ ${ }^{I}$ University of Nebraska at Kearney, Department of Biology, $240111^{\text {th }}$ Avenue, Kearney, Nebraska 68849, USA \\ ${ }^{2}$ Nebraska Game and Parks Commission, Kearney Field Office, $16171^{\text {st }}$ Avenue, Kearney, Nebraska 68847, USA
}

\begin{abstract}
A technique for mass-marking fish was evaluated that forces fluorescent pigment into dermal tissue with compressed air. A five month trial was conducted where mark retention, readability, and marking mortality were evaluated with six fish species that represent a variety of taxonomic groups. Approximately 100 of each species were marked; a percentage with fluorescent sprayed pigment and visible implanted elastomer (VIE) and the remaining with bilaterally distinct VIE tags. Marking mortality ranged from 0 to 100 percent and for three species mortality was size dependent. Mark retention declined at different rates for each species and ranged from 6 to 65 percent after five months. False-positive values and imperfect mark detection on poorly marked individuals affected retention. Growth of marked fish compared to unmarked control groups was significantly lower for two species. Because of inconsistency within and among species, fluorescent spray procedures need refinement and additional assessment prior to fisheries application.
\end{abstract}

Keywords: Fluorescent, mark readability, mark retention, mass-marking, marking mortality, pigment.

\section{INTRODUCTION}

Marks have broad applications in fisheries ecology for studies of life history characteristics, population dynamics, and behavior, including movement patterns [1-3]. When selecting suitable marking methods for studies, researchers must consider whether the marks meet the assumptions of the particular study models [3] and are time and costeffective $[1,4]$. Currently, numerous marking techniques are available that include fin-clipping, tagging, and chemical administration [5]. However, techniques are often unsatisfactory for one or more reasons that include effects on behavior or survival, poor retention periods, high cost of marking, or excessive handling of fish $[1,4]$.

A technique for mass application of marks by forcing fluorescent pigment into dermal tissue with compressed air from a handheld sandblasting gun was first reported by Jackson [6] and later refined by Phinney et al. [1]. However, the fluorescent pigment described in this earlier work is no longer commercially available. The technique offers a potentially fast and cost-effective method to mark fish when a limited number of individual marks are required [7]. The material becomes fluorescent when activated by ultraviolet light and can be read in the field without sacrificing the individual fish [1, 4]. Fluorescent pigment marking methods have generally been used for juvenile fish, with particular focus on stocked salmonids [1,7-12] but also a small number of warm-water species [13-16]. After a thorough review

\footnotetext{
*Address correspondence to this author at the Nebraska Game and Parks Commission, Kearney Field Office, $16171^{\text {st }}$ Avenue, Kearney, Nebraska 68847, USA; Tel: 308865 5310; Fax: 308865 5309;

E-mail: Keith.Koupal@Nebraska.gov
}

of the available literature, this fluorescent marking technique was deemed reliable for mass-marking fish; however our initial attempts proved inconsistent, meriting further examination of this technique.

Few studies have tested the effectiveness of sprayed fluorescent pigment to mark larger fish or have examined fish growth after marking $[7,13,17,18]$. The retention time of sprayed fluorescent marks has been observed to diverge depending on fish species, the size of fish when marked, the spraying pressure, and the pigment used [1]. Despite previously reported satisfactory results with little cost and effort this technique has lost favor with fisheries professionals in past decades. Currently, there are few published reports that describe poor results for any species studied. Complicating this assessment is the loss of the historic source for this fluorescent material which has been replaced with a material of a smaller grain size.

Therefore, the objective of this study was to evaluate the possible usefulness of available fluorescent pigment on six fish species that represent a variety of taxonomic groups. Secondary factors considered were the scale type, initial size of marked individuals, and effects of fluorescent marking on growth.

\section{MATERIALS AND METHODOLOGY}

Study area and fish collection.-Six species of fish that represent a variety of taxonomic groups were selected to be fluorescent spray marked. Fish species evaluated were channel catfish (Ictalurus punctatus Rafinesque), bluegill (Lepomis macrochirus Rafinesque), grass carp (Ctenopharyngodon idella Valenciennes), black bullhead (Ameiurus melas Rafinesque), plains topminnow (Fundulus sciadicus Cope), 
Table 1. Marking Mortality and Descriptive Characteristics of Six Species Marked with Fluorescent Spray Marks and Visible Implanted Elastomer (VIE) Tags. Marking Mortality was Defined as any Observed Mortality within 14 days of Marking Effort

\begin{tabular}{|c|c|c|c|c|c|c|c|}
\hline Fish Species & Scale Type & Size Class $^{\mathrm{a}}$ & $\begin{array}{c}\text { Mean Initial } \\
\mathrm{TL}(\mathbf{m m}) \pm \mathrm{SE}\end{array}$ & $\begin{array}{l}\text { No. Fish } \\
\text { Marked }^{\text {b }}\end{array}$ & $\begin{array}{c}\text { Marking } \\
\text { Mortality \% }\end{array}$ & $\begin{array}{l}\text { Mean TL }(\mathrm{mm}) \\
\text { Mortality } \pm \text { SE }\end{array}$ & Size Dependent ${ }^{\mathrm{c}}$ \\
\hline Orange throat darter & Ctenoid & Small & $47.6 \pm 0.99$ & $106(83)$ & $16 \%$ & $42.1 \pm 2.40$ & Small \\
\hline Bluegill & Ctenoid & Large & $75.8 \pm 0.41$ & $100(80)$ & $79 \%$ & $74.6 \pm 0.66$ & Random \\
\hline Plains topminnow & Cycloid & Small & $38.0 \pm 1.02$ & $108(87)$ & $11 \%$ & $48.1 \pm 3.12$ & Large \\
\hline Black bullhead & Scale-less & Large & $153.3 \pm 1.73$ & $80(65)$ & $0 \%$ & NA & Random \\
\hline Channel catfish & Scale-less & Large & $127.9 \pm 1.35$ & $100(80)$ & $9 \%$ & $115.4 \pm 4.20$ & Small \\
\hline \multicolumn{8}{|c|}{ Scale Type } \\
\hline Ctenoid & & & & $206(163)$ & $47 \%$ & & \\
\hline \multicolumn{8}{|c|}{ Size Class } \\
\hline Small & & & & $214(170)$ & $14 \%$ & & \\
\hline Large & & & & $380(305)$ & $47 \%$ & & \\
\hline
\end{tabular}

${ }^{a}$ Small size class represents fish with mean TL less than $50 \mathrm{~mm}$ and the large size class represents fish with mean TL greater than $50 \mathrm{~mm}$ at the time of marking

${ }^{b}$ Number of total fish marked and number of fish dual marked with both fluorescent marks and VIE tags

${ }^{c}$ Presence of size specific fluorescent pigment marking mortality

and orangethroat darter (Etheostoma spectabile Agassiz). Fish species selected represent three scale types (ctenoid, cycloid, and scale-less) and two size classes $(<50 \mathrm{~mm}$ total length [TL]; $>50 \mathrm{~mm} \mathrm{TL}$ ). Fish considered small at the time of marking and with limited growth potential were plains topminnow and orangethroat darter (Table 1). Large fish species at the time of marking and with greater potential growth were black bullhead, channel catfish, bluegill, and grass carp (Table 1).

Evaluated fish were fluorescent spray marked in May and were housed through October 2011 at two locations. Two approximately 1,5001 circular tanks ( $1.22 \mathrm{~m}$ diameter) provided with water from Calamus Reservoir at the Calamus State Fish Hatchery were used to house channel catfish, grass carp and bluegill. Other fish species were housed at the University of Nebraska at Kearney campus in two separate mesh cages placed in an approximately 1,9001 recirculating system that was provided with treated municipal water. During the study, all fish were fed three times per week approximately three percent mean body weight. Once per month 10 individuals were weighed and feeding ration was adjusted.

Marking technique.-Approximately 100 individuals of each species were marked, of which 80 percent received both fluorescent pigment spray marks and visible implanted elastomer (VIE) tags and 20 percent were marked only with a VIE tag. All VIE tags were injected on the dorsal surface of the fish; fluorescent marked individuals were marked with VIE tags anterior to the dorsal fin and fish without fluorescent marks were marked with VIE tags posterior to the dorsal fin.
Fish were marked in batches of 50 with a green fluorescent pigment (Risk Reactor Luminous Supplies; Santa Ana, California) with a diameter less than $50 \mu$. Fish were all sprayed at 120 psi with a JobSmart handheld abrasive blaster from a distance of approximately $75 \mathrm{~mm}$ while being held in a $60 \times 60 \times 20 \mathrm{~cm}$ wooden grading box covered with mesh net material [1]. The fluorescent mark was sprayed on each side of the fish [1]. Each fish was checked for initial mark retention by scanning for pigment in a dark box at a distance of 10 to $20 \mathrm{~cm}$ using a long-wave, ultraviolet light [18].

Marking mortality.-Mortalities were recorded bi-weekly and dead fish were frozen to allow assessment of individual mark history. Mortality within 14 days of the initial marking effort was assumed to be caused by the marking technique. Two-sample $t$-tests between lengths of surviving and dead individuals were used to determine if size-specific fluorescent pigment marking mortality occurred for any species $(\alpha$ $\leq 0.05$ ).

Retention rates and readability of fluorescent pigments.-Surviving fish were checked for fluorescent marks monthly for five months after marking by a single reader who was not aware of VIE mark distinction to evaluate fluorescent mark retention and readability. The reader delineated between fluorescent marked and unmarked individuals for each fish species. Reading accuracy was judged as correct or incorrect based upon the location of the VIE mark. The percentage of fish that continued to show fluorescent marks was calculated monthly to describe mark retention through time. Linear regression was used to quantify the rate of decrease in mark retention through time for each species. 


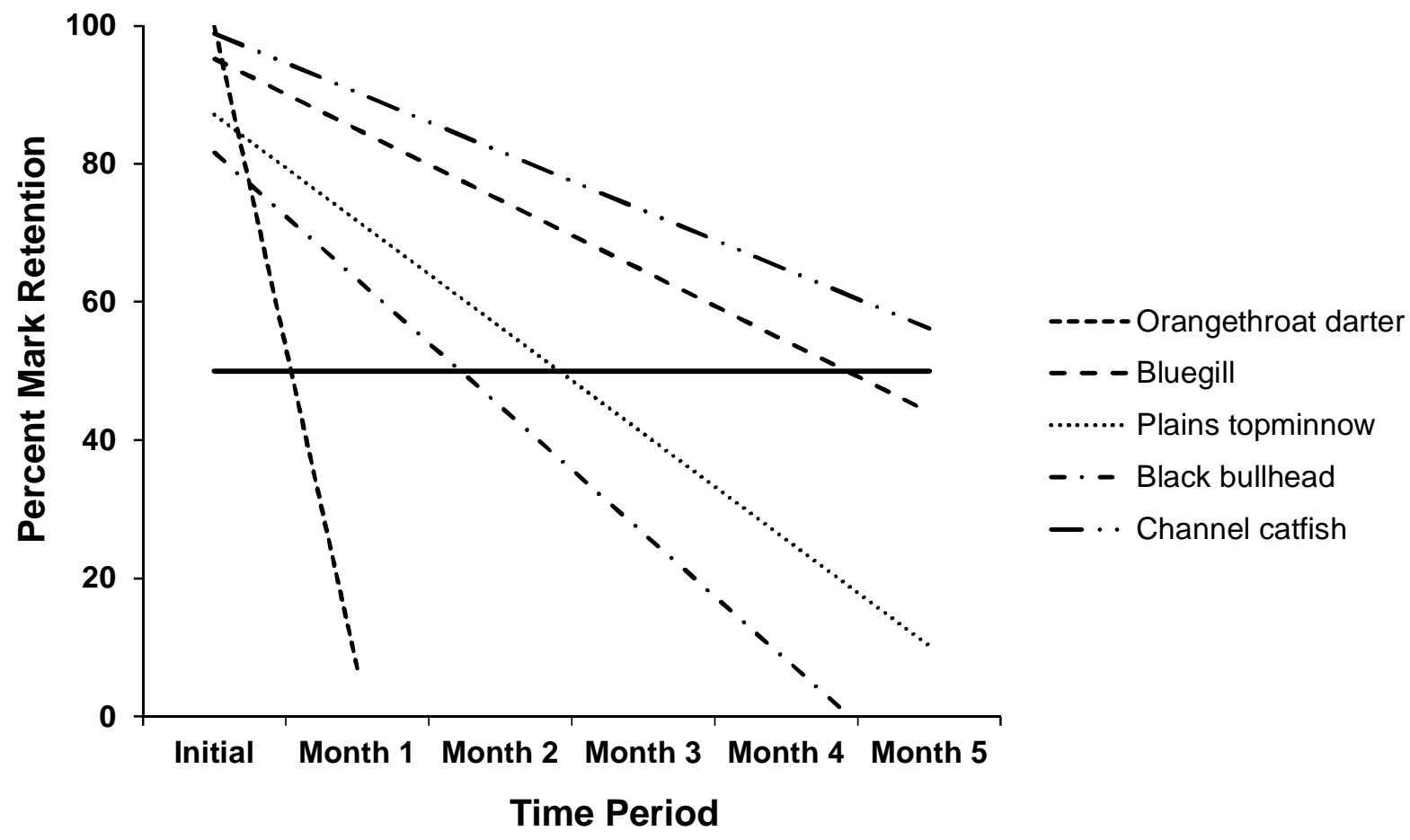

Fig. (1). Linear regression outputs depicting the rate of observed decline in mark retention for fish species marked with fluorescent spray pigments excluding grass carp for the five month trial. Resultant linear regression equations: $\mathrm{y}=-0.93 \mathrm{x}+1.93$ (orangethroat darter); $\mathrm{y}=-$ $0.1023 \mathrm{x}+1.0547$ (bluegill); $\mathrm{y}=-0.1537 \mathrm{x}+1.0247$ (plains topminnow); $\mathrm{y}=-0.1835 \mathrm{x}+1$ (black bullhead); and $\mathrm{y}=-0.0854 \mathrm{x}+1.074$ (channel catfish).

Mark readability was evaluated as the presence of falsepositive reader ratings and instances in which mark retention was observed to increase during subsequent monthly mark checks. At any time the reader incorrectly identified a fish as fluorescently marked when it was an unmarked individual the occurrence was recorded as a false-positive score. The total number of false-positive scores and percentage falsepositive scores of the total number of unmarked fish was calculated. Errors in readability were defined as instances where the retention rates of fluorescent marks were observed to increase through time and were described as the percentage increase.

Fluorescent marking effect on growth.-All fish were measured to total length ( $\mathrm{mm}$ ) prior to initial marking and monthly until the study's conclusion. Initial mean total length was compared within species and between marking strategies using two-sample $t$-tests assuming equal variance. A repeated measures ANOVA was used to test the null hypothesis that fish length was not different between marking treatments or among sampling months.

\section{RESULTS}

Marking mortality.-Control fish marked with only VIE tags exhibited zero mortality in the 14 day period defined as marking mortality for all species except grass carp for which 95 percent mortality was observed. Therefore, for species other than grass carp, mortality of dual marked individuals observed was deemed to be caused by the fluorescent marking technique. All experimental grass carp perished within 14 days of the initial marking (Table 1). The remaining experimental fish species exhibited $0-79$ percent mortality caused by the fluorescent marking technique with black bullhead and channel catfish having the lowest percentages (Table 1). Scale-less fish $(5 \%)$ and fish classified as small (14\%) were categories that demonstrated the lowest mortality when fluorescent spray marked (Table 1). All mortality for each species except orangethroat darter was observed in the first month of the trial. All orangethroat darter perished in the second month of the trial as a result of a malfunctioning filter.

Marking mortality with fluorescent pigment was observed to be size-specific for half of the species evaluated. Smaller individuals experienced the most marking mortality for orangethroat darter $(F=4.34, \mathrm{df}=97, P=0.04)$ and channel catfish $(F=6.96, \mathrm{df}=85, P=0.01)$, while marking mortality of plains topminnow was skewed to large individuals $(F=9.75, \mathrm{df}=92, P=0.02)$ (Table 1). For bluegill and black bullhead, there was no significant difference in length between surviving and dead individuals $(F=2.43, \mathrm{df}=141$, $P=0.12$ ).

Mark retention rates of fluorescent pigments.-Retention of VIE marks was 100 percent throughout the duration of the study for all species. After five months, fluorescent mark retention dropped below 75 percent for all study species; however, rates of decline varied among species (Fig. 1). Orangethroat darter, black bullhead, and plains topminnow had the lowest mark retention which dropped below 15 percent at the study's conclusion (Fig. 1). Channel catfish and bluegill had the highest mark retention after five months with 55 and 
Table 2. Presence of False-Positive Reader Ratings for Fish that were not Marked with Fluorescent Pigments Encountered During Five Months of Observation

\begin{tabular}{|c|c|c|c|c|}
\hline Fish Species & Number of Observations & $\begin{array}{c}\text { Total } \\
\text { False-Positive Scores }\end{array}$ & Monthly Range & Percent of Observations \\
\hline \hline Orangethroat darter & & 1 & $0-1$ & 3.0 \\
\hline Bluegill & 120 & 8 & $0-8$ & $0-1$ \\
\hline Plains topminnow & 66 & 1 & 0 & 0 \\
\hline Grass carp & 25 & 3 & $0-2$ & 3.6 \\
\hline Black bullhead & 96 & 4 & $0-2$ & 3.1 \\
\hline Channel catfish & 120 & & & \\
\hline
\end{tabular}

${ }^{\text {a }}$ Orangethroat darter were limited to two months of observations

Table 3. Observed Increase in Fluorescent Pigment Mark Retention and Corresponding Month in which the Observation Error was Encountered for each fish Species Fluorescent Spray Marked

\begin{tabular}{|c|c|c|}
\hline Fish Species & Month of Occurrence & Percent Increase in Observed Mark Retention \\
\hline \hline Orangethroat darter $^{\mathrm{a}}$ & None & 0 \\
\hline Bluegill & Five & 6 \\
\hline Plains topminnow & Three & 0 \\
\hline Grass carp & None & 1 \\
\hline Black bullhead & Three & 4 \\
\hline Channel catfish & Three & 6 \\
\hline
\end{tabular}

${ }^{a}$ Orangethroat darter were limited to two months of observations

65 percent of individuals retaining fluorescent pigments, respectively (Fig. 1). Bluegill had the lowest mean monthly decline in mark retention (7\%) while orangethroat darter showed the highest rate of monthly mark loss (93\%) (Fig. 1). Grass carp mark retention was unable to be quantified because of 100 percent marking mortality observed for fluorescent spray marked individuals.

Patterns of fluorescent pigment retention were observed for scale type and size class of evaluated fish. Ctenoid type scales displayed the highest mark retention (65\%) and declined at the lowest mean monthly rate (7\%). Fluorescent mark retention for fish lacking scales was 29 percent after the five month trial decreasing at a rate of 14 percent per month. Fish with cycloid scales exhibited the lowest mean fluorescent mark retention $(14 \%$ at the conclusion of the study) with an average decline of 17 percent per month. Fish species with a mean total length less than $50 \mathrm{~mm}$ (plains topminnow and orangethroat darter) at the time of marking had mean mark retention of 14 percent at the study's conclusion with a mean monthly decline in mark retention of 17 percent. Fish species with larger ( $>50 \mathrm{~mm}$ TL) initial body sizes when marked with fluorescent pigments had average mark retention of 41 percent which declined at a mean rate of 12 percent per month.

Readability of fluorescent marks.-Mark readability was affected by both false-positive reader ratings and an inability of fluorescent marks to be detected consistently. The total number of false-positive ratings varied among species and within species by month (Table 2). The total number of false-positive observations per species ranged from zero for grass carp to eight for bluegill (Table 2). The fish species with the highest percentage of false-positive scorings was bluegill ( $7 \%$ of observations), while the lowest was two percent of observations for unmarked plains topminnow individuals (Table 2 ).

Errors in the ability to recognize fluorescent marks affected perceived mark retention rates throughout the study. Fluorescent mark retention of four species was affected by an inability to consistently recognize fluorescent marks on poorly marked individuals. In month five, mark retention of bluegill was observed to increase by 40 percent from the prior month (Table 3). Other tested species had apparent increases in mark retention that ranged from one to six percent at various times throughout the study (Table 3 ).

Fluorescent mark effects on growth.-Fluorescent spray marks affected each treatment species uniquely. Initial total length was not significantly different between marking treatments for all species. Grass carp experienced too great of mortality to quantify mark effects on growth. Fish length increased over time for each of the study species except the orangethroat darter which was only sampled over two periods. Orangethroat darter lengths $(F=5.69$, df $=1,165, P=$ 0.02 ) were significantly lower for the VIE marked individuals when compared to fluorescent pigment marked individuals after two months. However, it is likely that this result is because fluorescent marking mortality of this species was skewed to smaller individuals and that there was zero mortality of VIE only marked fish (Table 1). Plains topminnow 
lengths $(F=7.43, \mathrm{df}=1,321, P=0.01)$ were also found to be significantly lower for VIE only marked fish. This result was supported as no significant differences between mortality of VIE marked fish and surviving VIE marked fish existed throughout the study $(F=0.73$, df $=8, P=0.42)$ and that marking mortality was skewed to large fluorescentpigment-marked individuals. Black bullhead $(F=5.76, \mathrm{df}=$ $1,475, P=0.02)$ and bluegill lengths $(F=5.71, \mathrm{df}=1,278$, $P=0.018$ ) were significantly lower for fluorescent marked individuals at the trials conclusion. No significant difference between length of fluorescent marked black bullhead mortalities and lengths of fluorescent marked bullheads was found. Total length of fluorescent marked bluegill mortalities and surviving fluorescent marked bluegill were significantly different $(F=28.69, \mathrm{df}=25, P<0.0001)$ and was skewed to smaller individuals. Channel catfish length was not significantly different between marking treatments $(F=0.62, \mathrm{df}=$ $1,558, P=0.43)$.

\section{DISCUSSION}

The technique for fluorescent spray marking described in this study was efficient, involving relatively little time, effort and cost compared to other marking methods. For the current study, the total time required for a two person crew to fluorescent spray mark a total of 475 fish was approximately 30 min. However, this technique has achieved rates of marking that exceed 35,000 fish per hour when marking Chinook salmon (Oncorhynchus tshawytscha Walbaum) and rainbow trout (Oncorhynchus mykiss Walbaum) [18]. Although, the strength of this technique is the ability to rapidly mark many fish, alternative techniques such as marking individual fish with a known amount of pigment and in a uniform pattern may increase the mark retention and survival.

The estimated cost to fluorescent mark 1,000 Chinook salmon was reported as approximately $\$ 3$ [1], which is much lower than the cost associated with marking in the current study. In total, the cost to mark 475 fish was in the current study was nearly $\$ 70$. The availability of this fluorescent pigment has decreased and prices have increased since prior comparative studies. The advantage of mass-marking fish was not fully realized in this study because of care taken to mark separate species.

Marking mortality in the current study was acceptable for some species and intolerable for others. In all cases mortality related to the marking technique ceased within $72 \mathrm{~h}$ which is comparable to Chinook salmon where all marking mortality occurred in $24 \mathrm{~h}[10,11,19]$. Grass carp mortality appeared to be the result of disease that probably was aggravated by excessive damage to the soft integument, high water temperature, and crowding. Susceptibility to disease has been observed after fluorescent spray marking walleye (Sander vitreus Mitchill) and brook stickleback (Culaea inconstans Kirtland) and in each case marking mortality exceeded 66 and 68 percent $[11,20]$. The mortality associated with fluorescent spray marks varied considerably for the remaining species in the current study. This is consistent with mean marking mortality percentages reported for a variety of species including salmonids which have ranged from 0 to 97 percent, brook stickleback (0.3-68\%), largemouth bass (Micropterus salmoides Lacépède) (8\%), and fathead minnow (Pimephales promelas Rafinesque) mortality (0\%) [10, 11,
$14,17,19,20]$. Prior assessments of marking mortality on channel catfish, the only species previously evaluated for mortality, reported marking mortality near eight percent which is similar to the current studies results of nine percent [11].

Marking mortality seemed to be dependent on fish size when marked and scale type. Mortality was higher for smaller sized channel catfish and orangethroat darter. Similar results were found with salmonid individuals where mortality increased with decreasing size of marked individuals [17, 19]. In the current study, however; larger plains topminnow and the large size class $(>50 \mathrm{~mm} \mathrm{TL})$ were more likely to perish as a result of the fluorescent spray marks. Considerable variation between trials exist in each case that multiple groups of fish of the same species were marked due to seemingly uncontrollable subtle difference in the marking procedure $[10,11,14,17,19,20]$. In prior studies and the current investigation, suffocation appeared to be a major cause of mortality as there was much compacted pigment around the gills of dead fish [11].

Considerable variation of the extent of fluorescent mark retention exists among and within taxonomic groups that have been previously evaluated. Our study demonstrated mark retention less than 75 percent for all species evaluated after five months with channel catfish and bluegill having the highest retention rates. Previous studies found retention for some species to far exceed our findings with retention percentages that exceed 99 percent for bluegill and range from 93 to 100 percent for channel catfish [11, 13, 21]. Comparatively fluorescent mark retention of other previously evaluated fish species assessed varied substantially; brook stickleback (declined rapidly to $2 \%$ ), grass carp (61\% at commercial harvest), largemouth bass (after nine months was $87 \%$ ), salmonids (ranging from 75 to $98 \%$ for up to two years), and fluorescent marks on fathead minnow were expected to last their lifetime [7, 9, 10,14, 17-22]. It is clear that much inconsistency exists with the mark retention of fluorescent spray techniques as seen with the current study and comparisons to prior attempts.

A potential source for the observed reduction of fluorescent mark retention in the current study could be the result of using smaller fluorescent pigments than previous studies which are presumably more easily moved or broken down by the fish immune system. The larger size pigments used in historic studies were not available for this study. Potentially, the lack of availability of the larger pigment has decreased the use of this marking technique in fisheries sciences. The granular size $(50-350 \mu)$ appears best suited for nearly all species as the smaller sizes do not appear to penetrate sufficiently well for continued retention and because the particles used were not coated with an inert substance it may have elicited an immune response [9]. Previous evaluation of particle size has resulted in retention rates for salmonids of 6 to 89 percent for powdered pigments similar to one used in the current study and 28-100 percent for the larger granules with increased retention corresponding to increased pressure and subsequent penetration force [1]. However, there is a balance between increased spraying pressure, which increases mark retention through deeper particle penetration, and the associated increase in marking mortality for a variety of fishes $[1$, 
$7,9,20]$. The pressure selected for the current study is typical of previous evaluations and has been considered suitable for species with these scale types, however further evaluation may demonstrate more appropriate species-specific spraying pressures that may provide suitable terms of mark retention and survival.

Although these marks are observable by trained individuals, pigment is reduced through time, making recognition difficult as often lone particles remain. The current findings demonstrated that errors occur in two varieties with fish marked with fluorescent pigments: false-positive ratings and errors of readability. For each species evaluated other than grass carp between 0 and 10 percent of the total number of unmarked fish evaluated were incorrectly labeled as fluorescent marked. This error has been discussed in a prior study in which the authors speculated that unmarked fish may be incorrectly classified as marked because of the natural fluorescence of bony parts or stray particles that can be attached during handling [20]. Errors of readability were more difficult to quantify, however were noticed at times when dramatic increases in mark retention were observed. Prior studies have found that deterioration of fluorescent marks can be subject to observation error over time as was found when correct identification of the combinations of different colored pigments was subject to high observation error rates for marked Chinook salmon and rainbow trout [18]. Often the source of this observational error are situations where few marks remain present on the fish such as with brook stickleback where marked fish were consistently not detected [20] and fathead minnow [14] in which "very few" pigments were secured.

Growth of fish after fluorescent spray marking has rarely been evaluated. Black bullhead and bluegill were found to grow at lower rates when marked with fluorescent pigments compared to control groups. Analogous results exist in fluorescent marking trials involving largemouth bass in which zero growth was observed after 188 days and for marked yearling lake trout (Salvelinus namaycush Walbaum) where growth was on average $7 \mathrm{~mm}$ less than control groups [11]. In another case, marking was found to have little effect on the growth of brook stickleback; but marked fish had a significantly lower mean condition factor than unmarked fish after one month [20]. However, variation in results has occurred and other studies have demonstrated that fluorescent spray marks have no effect on fish growth [10].

Fluorescent mark retention was observed to decrease with fish growth in the current study which is similar to results of prior long-term fluorescent mark retention studies. Fluorescent mark retention for both Chinook salmon and rainbow trout was reduced with time likely because of fish growth, however over a period of years rather than months [18]. Rapid growth of largemouth bass has also been suggested to contribute to observed declines in fluorescent mark retention [13]. At times when fish size has been observed to affect fluorescent mark effectiveness, quality mark retention periods have been obtained when the fish is marked after it reaches a certain threshold size [17].

\section{CONCLUSION}

Many past studies have described fluorescent spray marks as permanent when used for a variety of fish species. However, results from prior and current fluorescent marking trials are evidence to the inconsistency with variable marking mortality, mark retention, and questionable readability within and among species. Use of fluorescent spray marks for each of the species evaluated seems inappropriate with the lone exception being channel catfish although inconsistent results when compared to historic trials raises doubt to the reliability of the technique. Although channel catfish were marked successfully with little mortality and no effect on growth, they retained few particles per fish therefore being susceptible to observation error. Failure to detect all of the marked fish in a sample (a form of mark loss) is a problem with this marking technique that has not been previously recognized and quantified. Pigment size may be the most critical aspect for successfully marking fish; however, the inadequate availability of the larger granule pigment ensures that future application of this marking technique will likely be limited. Results of long-term retention of fluorescent pigment marks have been variable and often low for many species and at times have varied in subsequent trials studying the same species $[7,9,17,21]$. For that reason, we suggest that fluorescent spray marking be used with caution as a marking technique until such time that reliable and repeatable species specific methods be developed for the pigment commercially available.

\section{CONFLICT OF INTEREST}

None declared.

\section{ACKNOWLEDGEMENTS}

The authors would like to thank the Nebraska Game and Parks Commission Fisheries Division, University of $\mathrm{Ne}-$ braska at Kearney Biology Department and Nebraska State Wildlife Grant Program (T2F8R001) for project support. Special thanks are offered to Jacob Wirtz for mark reading and field assistance. Staff from Rock Creek State Fish Hatchery and Calamus State Fish Hatchery, both in Nebraska, provided technical advice and project support with marking fish, housing fish, monitoring tanks and water flow and housing equipment. Specific individuals from these hatcheries that warrant mention include: Gerald Coates, Hal Walker, Brett Brunken, and Doug Kapke. Assistance with marking and maintenance of housing equipment was also aided by Chris Uphoff, Mike Cavallaro, Seth Lundgren, and John Howard.

\section{REFERENCES}

[1] Phinney DE, Mathews SB, Dahlberg ML. Mass marking young salmonids with fluorescent pigment. Trans Am Fish Soc 1967; 96(2): 157-62.

[2] Guy CS, Blankenship HL, Nielsen LA. Tagging and marking. In: Murphy BR, Willis DW, Eds. Fisheries Techniques. $2^{\text {nd }}$ ed. Bethesda: Am Fisheries Soc 1996; pp. 353-79.

[3] Curtis JMR. Visible implant elastomer color determination, tag visibility, and tag loss: potential sources of error for mark-recapture studies. N Am J Fish Manag 2006; 26: 327-37. 
[4] Gaines PC, Martin CD. Feasibility of dual-marking age-0 Chinook salmon for mark-recapture studies. N Am J Fish Manag 2004; 24 : 1456-9.

[5] Parker NC, Giorgi AE, Heidinger RC, et al, Eds. Fish-marking techniques. Am Fisheries Soc Sympos 7, Bethesda 1990.

[6] Jackson CF. A technique for mass-marking fish by means of compressed air. USA: NH Fish and Game Dept and Eng Station Unviersity of Hampshire 1959.

[7] Leskelä A. Prolonged retention of fluorescent pigment spray marks in European whitefish, Coregonus lavaretus (L.). Fish Manage Ecol 1999; 6: 255-7.

[8] Phinney DE, Mathews SB. Field test of fluorescent pigment marking and finclipping of coho salmon. J Fish Res Board Can 1969; 26: 1619-24

[9] Phinney DE, Mathews SB. Retention of fluorescent pigment by coho salmon after two years. Progress Fish-Cult 1973; 35(3): 1613.

[10] Phinney DE Growth and survival of fluorescent pigment marked and finclipped salmon. J Wildl Manage 1974; 38(1): 132-7.

[11] Bartow F. Fluorescent pigment marking of seven Minnesota fish species. Investigational Report No. 393. Minneapolis: Minnesota Department of Fisheries 1987.

[12] Hayes MC, Focher SM, Conto CR. High-pressure injection of photonic paint to mark adult Chinook salmon. N Am J Aquac 2000: 62: 319-22.

[13] Ware FJ. Mass marking warm water fish by compressed air and fluorescent pigment. Proceedings of the Annual Conference of the
Southeast Association of Game and Fish Commissioners 1968; vol. 22: pp. 339-42.

[14] Andrews AK. Survival and mark retention of a small cyprinid marked with fluorescent pigments. Trans Am Fish Soc 1972 101(1): 128-33.

[15] Rinne WE, Deacon JE. Fluorescent pigment and immersion stain marking techniques for Lepidomeda mollispinis and Cyprinodon nevadensis. Trans Am Fish Soc 1973; 102: 459-62.

[16] Strange CD, Kennedy GJA. Fluorescent pigment marking of cyprinids. Fish Manage 1984; 15(2): 67-9.

[17] Strange CD, Kennedy JA. Evaluation of fluorescent pigment marking of brown trout (Salmo trutta L.) and Atlantic salmon (Salmo salar L.). Fish Manage 1982; 13(3): 89-95.

[18] Evenson MD, Ewing RD. Long-term retention of fluorescent pigment marks by spring Chinook salmon and summer steelhead. N Am J Fish Manage 1985; 5: 26-32.

[19] Hennick DP, Tyler RW. Experimental marking of emergent pink salmon (Oncorhynchus gorbuscha) fry with sprayed fluorescent pigment. Trans Am Fish Soc 1970; 99(2): 397-400.

[20] Moodie GEE, Salfert IG. Evaluation of fluorescent pigment for marking a scaleless fish, the brook stickleback. Prog Fish-Cult 1982; 44(4): 192-5.

[21] Pierson JM, Bayne DR. Long-term retention of fluorescent pigment by four fishes used in warmwater culture. Prog Fish-Cult 1983; 45(3): 186-8.

[22] Engelhardt WH. Retention of fluorescent pigment marks by two strains of largemouth bass. Trans Am Fish Soc 1977; 106(1): 64-6.

Received: December 10, 2012

(C) Schumann et al.; Licensee Bentham Open.

This is an open access article licensed under the terms of the Creative Commons Attribution Non-Commercial License (http://creativecommons.org/licenses/by-nc/3.0/) which permits unrestricted, non-commercial use, distribution and reproduction in any medium, provided the work is properly cited. 